\title{
Approaches to researching digital-pedagogical competence development in VE-based teacher education
}

\author{
Mirjam Hauck', Andreas Müller-Hartmann², Bart Rienties ${ }^{3}$, and Jekaterina Rogaten ${ }^{4}$
}

Abstract

Lor the past two decades, Virtual Exchange (VE) has enjoyed increasing popularity
in university education, including initial (language) teacher education programmes
(O'Dowd, 2018). Collaborating online with colleagues and students from different cultural backgrounds and educational systems has allowed trainees to experience and reflect on issues related to technology and pedagogy in authentic linguistic and intercultural contexts. In 2017/2018, the Evaluating and Upscaling Telecollaborative Teacher Education (EVALUATE) project - an Erasmus+ funded European Policy Experimentation (EPE) - collected and analysed data from VEs across the curriculum involving over 1,000 participants at Initial Teacher Education (ITE) institutions in Europe and beyond. Here, we specifically focus on the impact of VE on their digital-pedagogical competence development. Following a mixed method design we used the Technological Pedagogical Content Knowledge (TPACK) work of Mishra and Koehler (2006) and Schmidt et al. (2009) in a pre-post-test manner. These were complemented by qualitative content analysis of prompted diary entries at key stages during the exchanges to collect further evidence of existing and emerging digital-pedagogical skills among the trainees. Based on one case study of a German-Polish EVALUATE exchange we will exemplify the aforementioned research methods and associated challenges. We will illustrate the urgent need for initial and in-service teacher education that combines technology and pedagogy and argue for

\footnotetext{
1. The Open University; mirjam.hauck@open.ac.uk

2. Pädagogische Hochschule Heidelberg; andreas.mueller-hartmann@ph-heidelberg.de

3. The Open University; bart.rienties@open.ac.uk

4. University of the Arts London; jekaterina.rogaten@open.ac.uk
}

How to cite this article: Hauck, M., Müller-Hartmann, A., Rienties, B., \& Rogaten, J. (2020). Approaches to researching digital-pedagogical competence development in VE-based teacher education. Journal of Virtual Exchange, 3(SI), 5-35. https://doi.org/10.21827/jve.3.36082 
VE as an ideal context to this effect. Finally, we will demonstrate how the chosen research approach has contributed to providing the kind of evidence required by education administrators and policy makers for a systematic integration of VE into teacher education programmes.

Keywords: teacher education; digital-pedagogical competence; mixed method design; TPACK and learner diaries; evidence; education administrators; policy makers.

\section{Introduction}

VE provides learners with opportunities to interact with one another through communication modes offered by online technologies and to collaborate on joint projects in transnational teams (The EVALUATE Group, 2019). Recent years have seen increasing interest in VE in initial language teacher education programmes (e.g. Fuchs, Hauck, \& Müller-Hartmann, 2012; Müller-Hartmann, 2006) as it allows teacher trainees to discover, experience, and reflect on the multi-layered aspects of their own techno-pedagogy (Desjardins \& Peters, 2007) in authentic linguistic and intercultural contexts (Hauck \& Kurek, 2017). However, most studies reported in the literature are small scale, one off projects (The EVALUATE Group, 2019).

The EVALUATE project (www.evaluateproject.eu) was an Erasmus+ funded EPE carried out in 2017/2018 by a consortium of researchers, a university network (Compostela Group), and public authorities ${ }^{5}$. Using qualitative and quantitative research methodologies, the project collected and analysed data from VEs across the curriculum involving over 1,000 student teachers in ITE in Europe and beyond. It was the first large scale study designed to demonstrate the potential learning gains of a significant number of participants. The exchanges followed the Progressive Exchange Model which has been widely used in VE research and practice to date (O'Dowd \& Lewis, 2016; O'Dowd \& Ware, 2009): participants engaged in three interrelated tasks, moving from information exchange, comparing and analysing cultural practices, and finally to working on a collaborative product.

The EPE aimed to explore the interrelationship between student teachers' participation in VEs and the development of competences needed to teach, collaborate, and innovate effectively in an increasingly connected and digitalised world (The EVALUATE Group, 2019). A recent survey

5. For a list of all consortium members, see here: http://www.evaluateproject.eu/consortium/ 
indicated that only $20-25 \%$ of students in Europe are taught by teachers who are confident in using technology in the classroom (European Commission, 2015a). Yet, teachers need to be prepared for the classrooms of tomorrow and equipped with the skills and competences to teach in culturally diverse contexts, to collaborate across disciplines, and to use technology in innovative ways. However, online technologies are often used as a remedial tool and innovative approaches to technology integration are often limited to the pedagogical activities of a few isolated practitioners (European Commission, 2015b). Thus, those responsible for ITE in Europe have to find ways to better prepare the teachers of tomorrow. To this effect, the European Council and Commission on the implementation of the Education and Training 2020 urges teacher training programmes to "reap the benefits of new [Information and Communication Technology (ICT)] developments and adopt innovative and active pedagogies, based on participatory and project based methods” (ET2020, 2015, p. 5), defining aspects of VE pedagogy.

Here we report on findings from one specific VE in relation to one of the three sub-questions ${ }^{6}$ the EVALUATE EPE set out to address, notably what impact will VEs have on student teachers' digitalpedagogical competence development?

To answer this question, we picked up a thread of mostly qualitative investigations into language teacher education and VE started over a decade ago and highlighting the beneficial interrelationship between VE and ICT competence development in pre- and in-service teachers (e.g. Arnold \& Ducate, 2006; Hauck, 2007; Müller-Hartmann, 2006). However, the current study reflects a mixed method approach and is informed by the TPACK work by Mishra and Koehler (2006) and subsequently Schmidt et al. (2009).

Our contribution starts with an overview of the literature connecting VE-based teacher education and technological competence development before providing an insight into TPACK-based research (Section 2). Next, we outline our methodology: participants and settings, the procedural approach, research instruments and data analysis (Section 3). The methodology is exemplified through a German-Polish EVALUATE VE. This is followed by a presentation and discussion of the results in relation to our research question (Section 4). In our concluding remarks (Section 5), we will make the case in favour of the chosen methodology as apt to provide the evidence required by education decision makers for a systematic integration of VE into (language) teacher education programmes.

6. These are the other two sub-questions: what impact will virtual exchange have on student teachers' intercultural competence? What impact will virtual exchange have on student teachers' foreign language competence (this question was dealt with in contexts where foreign language learning was a part of the teacher education courses)? 


\section{Literature review}

In this review, we consider published research on the nexus between VE, more specifically telecollaboration, and technological competence development which has been mostly guided by a qualitative paradigm. We also look at some of the literature on TPACK as it informed the quantitative approach in EVALUATE.

\subsection{VE and technological competence development}

A considerable amount of VE research has been carried out in university foreign language education. As Helm (2014) reminds us, "[h]undreds of journal articles have been published, dedicated volumes (Belz \& Thorne, 2006; Dooly, 2008; Guth \& Helm, 2010; Kern \& Warschauer, 2000; O’Dowd, 2007) and journal special editions (Belz, 2003; Lewis, Chanier, \& Youngs, 2011)” (p. 45). The reported learning benefits cover areas as diverse as learner autonomy (e.g. O’Rourke, 2006), linguistic accuracy and fluency (Kinginger \& Belz, 2005; Ware \& O’Dowd, 2008), intercultural awareness (O’Dowd, 2006), online intercultural communication skills (Müller-Hartmann, 2006; O’Dowd \& Ritter, 2006), and electronic literacy (Hauck, 2007).

It has been shown, for example, that computer-mediated communication which usually forms the backbone of a VE, affords teachers the opportunity to use digital tools themselves before teaching with them and that it can increase their confidence in technology integration into their classrooms (Arnold \& Ducate, 2006). Furthermore, Hauck (2007) established the interdependence between multimodal communicative competence and intercultural communicative development in telecollaboration. She suggested that participants - including language teacher trainees - with full awareness of the affordances of many modes and media were "likely to experience comparatively higher levels of intercultural knowledge gain in telecollaboration” (Hauck, 2007, p. 221). Fuchs et al. (2012) and Hauck and Kurek (2017) showed that multimodal communicative competence, and the development of intercultural communicative competence development and digital literacy skills through VE, were interdependent and argued for VE task design and teacher preparation drawing attention to this interrelationship. Moreover, Fuchs et al. (2012) explored multiliteracies training including training in digital literacies - understood as one of the component literacies of multiliteracies - in a VE context. They hypothesised that such training contributed to what Fuchs (2006) calls the tutors' professional literacy, more recently conceptualised as a core dimension of Kurek and Turula's (2014) ‘digital teacher autonomy’. The authors drew on data from a four-way VE between teacher trainees and language learners to illustrate why and how VE provided the ideal setup for fostering multiliteracies and thus digital literacies skills development. 
Similarly, Helm (2014) pointed to the different modes of Web 2.0 tools in which learners can communicate, exchange, compare, and contrast information, and which facilitate the collaborative construction of knowledge in the form of new cultural practices or artefacts, such as blogs and wikis. “These are complex contexts”, Helm (2014) observed, "in which learners have to learn to operate, and require the development of digital literacies both on the part of learners and educators” (p. 46). A challenge which also applies to teacher trainees.

Hauck and Kurek (2017) started from the premise that digital literacies development should be an integral part of pre- and in-service training programmes for language teachers. VE, they suggest, provide an optimal setting to this effect as it is, by definition, based on the use of networked technologies, and thus facilitates 'on-the-job' training in digital literacy skills (Helm, 2014). A view shared by Guikema and Menke (2014) who asserted that "[t]eachers who have experienced collaborative digital communities are less likely to use technology as an instructional tool and instead view it as an object of instruction” (p. 267).

Kurek and Hauck (2014) represented a first attempt at a task framework for explicit training in digital literacies. The framework allows students - thus also teacher trainees - to move along a continuum from informed reception of multimodal input through thoughtful participation in opinion-generating activities and on to creative contribution of multimodal output. Together with the approach suggested by O'Dowd and Ware (2009) for sequencing activities in telecollaboration, this framework guided the task progression developed for the EVALUATE study.

Despite these efforts, a systematic, large scale study drawing on both qualitative and quantitative methods and providing evidence for the added value of VE in (language) teacher education in terms of digital-pedagogical skills development was - until recently - a desideratum.

Furthermore, Lawless and Pellegrino (2007) and Stes, Min-Leliveld, Gijbels, and Van Petegem (2010) urged for more robust research of the effects of teacher training, and to move the focus of research on teacher training from mere learning satisfaction of a particular training programme to an understanding of whether participants actually learned something relevant, valuable, and applicable to their daily practice. For example, in a meta-review of 36 (primarily US) studies in higher education, Stes et al. (2010) concluded that only three studies measured the impact of teacher training on teachers' behaviour using a pre- and post-test method. Hence "the challenge is not only designing effective, pedagogically sound professional development”, Rienties, Brouwer, and LygoBaker (2013b) conclude, "but also demonstrating the impact that this has had" (p. 123). This was a gap the EVALUATE project set out to plug. 


\subsection{TPACK}

In EVALUATE, the TPACK framework was used to address the aforementioned research question from a quantitative angle.

\subsubsection{The TPACK framework}

TPACK aims to guide and support teachers' digital-pedagogical competence development understood as the ability to plan, implement, and evaluate the use of technologies (online tools and applications) in their classes (Koehler \& Mishra, 2005). The framework (Figure 1) is designed to capture how a teacher's understanding of content, pedagogy, and technology interrelate and impact on effective teaching.

Figure 1. TPACK image (http://matt-koehler.com/tpack2/using-the-tpack-image/)

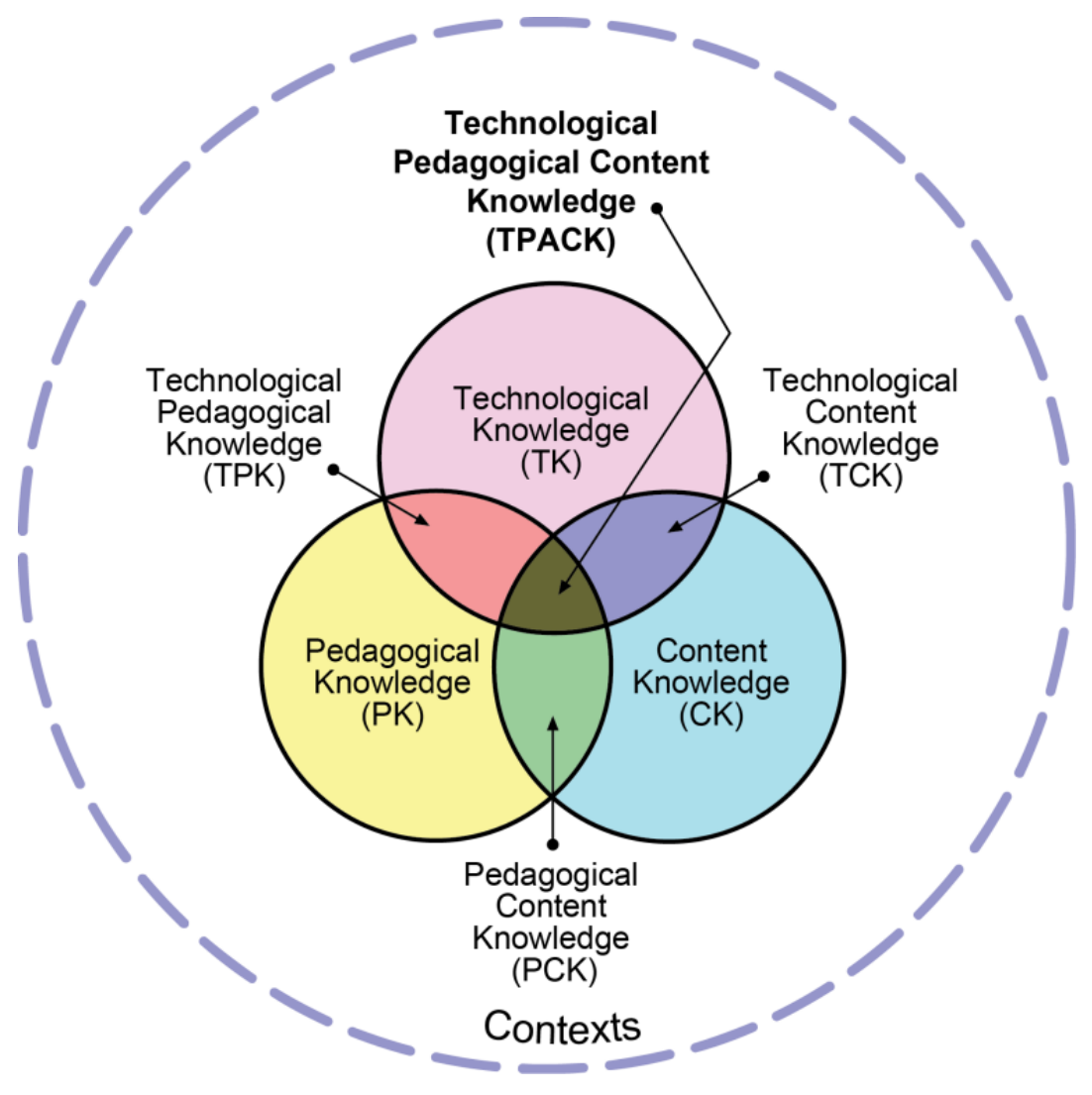


Koehler and Mishra (2005) distinguish between three main types of knowledge - Content (CK), Pedagogy (PK), and Technology (TK) - and are particularly interested in the types of knowledge that lie at the intersections between these three areas: Pedagogical Content Knowledge (PCK), Technological Content Knowledge (TCK), Technological Pedagogical Knowledge (TPK), and TPACK.

\subsubsection{TPACK-based studies}

A range of studies have successfully used TPACK to measure teachers' growth in TPACK skills in particular. For example, in a study amongst 889 pre-service teachers in Singapore using a shortened version of Schmidt et al. (2009), Chai, Koh, and Tsai (2010) found that TK, PK, and CK were all significant predictors of pre-service teachers' TPACK, with PK having the largest impact. In an online teacher training programme in the Netherlands across 73 academics from nine higher educational institutions, Rienties et al. (2013a) used a pre-post-test design with TPACK, and found that TPACK skills increased substantially using VE, whereby teachers interacted on a weekly basis for about ten weeks and discussed their teaching practice with peers from other universities.

Chai, Koh, and Tsai (2013) reviewed 74 journal papers investigating ICT integration based on TPACK. They acknowledge the proliferate TPACK-informed research among teacher educators with an interest in educational technology showing a positive impact on teachers' capability to infuse ICT into their classrooms. Yet, the authors also point to the fact that studies drawing on TPACK to promote deeper change in education are missing. Indeed a follow-up review by Rosenberg and Koehler (2015) of 193 TPACK studies showed that only 36\% of studies included context in their approach. As argued by Rosenberg and Koehler (2015), the context in which learners and teachers operate has a substantial influence on their TPACK development. This was one of the aims of EVALUATE: to provide evidence for the value of engaging future teachers in innovative applications of online technologies which involve their use in collaborative, student-centred approaches to learning such as VEs.

Similar to the EVALUATE study, the majority of contributions considered by Chai et al. (2013) advocate a constructivist-oriented pedagogy grounded in project-based or inquiry-based learning. Constructivism, they observed, continues to provide a strong theoretical backdrop for technologybased learning and teaching (e.g. Jonassen, Peck, \& Wilson, 1999). This also applies to VEs.

Chai et al. (2013) also summarise findings from intervention studies based on TPACK and which required participants to plan or design lessons for ICT integration. The latter was also one of the aims in EVALUATE. The studies considered by Chai et al. (2013) underscore - among other things the importance of providing metacognitive support for pre-service teachers expected to design ICT 
lessons (e.g. Kramarski \& Michalsky, 2009, 2010; cited in Chai et al., 2013). Independent of the chosen approach for the intervention, the great majority (28 out of 32 studies) reported positive outcomes. Only four studies reported mixed outcomes (Groth, Spickler, Bergner, \& Bardzell, 2009; Nicholas \& Ng, 2012; Niess, 2005; So \& Kim, 2009; cited in Chai et al., 2013). These highlight the following factors influencing a deeper and wider integration of ICT by teachers:

- doubts with regard to the usefulness of technology in facilitating student learning;

- gaps between knowledge, beliefs, and action related to ICT among pre-service teachers in particular; and

- perceived difficulties in designing authentic and engaging problems and appropriate scaffolding for their subject area.

In EVALUATE, the last factor was mitigated through ready-made task sequences participants could choose from.

Chai et al. (2013) concluded that there was a strong interdependence between teachers' beliefs, competencies, and context and that "enhancing teachers' TPACK is a necessary but insufficient condition for widespread pedagogical use of ICT” (p. 39). There are intrapersonal factors that need to be considered, such as underlying limiting beliefs and a lack of creativity needed to design suitable scenarios. Equally important are institutional challenges such as lack of curriculum time, planning time, and examination constraints which need to be addressed. As we will show (Section 4) some of these also surfaced in EVALUATE.

Interestingly Chai et al. (2013) argued for the need to engage teachers in 'learning by design' due to its constructivist and epistemic nature and because it promotes a propensity for 'designerly thinking' in teachers. "Equipped with both traditional and design epistemology", they put forward teachers will "be able to better engage students to learn with technology" (Chai et al., 2013, p. 40). The task sequences provided by the EVALUATE researchers for the participants were developed to foster such 'designerly thinking'?

As a focus of future research, they suggest investigations into the interrelationship between teachers' experience of 'learning by design' and its impact on their epistemological and/or pedagogical beliefs and classroom practices in terms of technology integration. While this was not an explicit focus of EVALUATE, some of the data collected and analysed does, in fact, testify to this

7. See section 6.2.2 in the full EVALUATE report for details on the task sequences and their implementation (https://www.evaluateproject.eu/evlt-data/ uploads/2019/03/EVALUATE_EPE_2019.pdf) 
effect, at least as far as pre-service teacher beliefs are concerned. In Section 4 we draw on data from one VE to illustrate this.

Kimmons (2015) laments a general, non-critical utilisation of TPACK and sets out to explore the affordances and limitations of the framework for researchers and teachers. He draws attention to the following issues: The need to:

- overcome the framework's technocentrism which may distract from important considerations related to technology integration, such as, for example, student learning;

- clarify the logical relationships between the base components, the hybrid components, and TPACK itself;

- move beyond subjective language related to technology integration in evaluation tools (e.g. 'appropriately' or 'effective technology integration'; and

- move beyond the 'what' of technology integration (e.g. what is being done, and what tools are used) and to consider the 'why' and 'how' of technology integration, and to integrate these understandings back into TPACK by asking questions such as 'why is this effective' and 'how is this impacting learning?'.

This, he posits, will allow researchers of technology integration to counteract concerns related to technocentrism. In EVALUATE, most of the issues highlighted by Kimmons (2015) were addressed through prompted reflections in the learner diaries kept by the participants. These explicitly focused on the 'why' and 'how' of technology integration.

\section{Methodology}

To address the research question - what impact will VE have on student teachers' digital-pedagogical competence development? - we used a mixed methods approach combining quantitative data to measure competence development, while qualitative data were used to explore why VE had the impact it did.

\subsection{Participants and settings}

In line with recommendations by Torgerson and Torgerson (2008), Stes et al. (2010), and Rogaten et al. (2019), a pre-post-test research design was implemented. The overall sample consisted of 1,018 participants, with 906 (89\%) participants completing the pre-test and 638 (63\%) participants completing the post-test, with $57 \%$ of participants completing both the pre- and post-test, which 
represents a good response rate for a longitudinal social science study. In total, 25 VEs took place between participants from 34 ITE institutions in 16 different countries. The average VE lasted for 67.09 days ( $S D=26.97$ days).

Here, we focused on VE 1 which had a relatively low initial digital competence score (see Figure 3), but nonetheless showed a substantial increase during the exchange. Furthermore, we had access to fine-grained data from this exchange as one of the authors of this article was part of the teaching team. While this could be perceived as creating an epistemological challenge in terms of this colleague's involvement as both a teacher and a researcher, the risk of bias was mitigated by the fact that three more colleagues were involved in analysing the overall data set. Thus the methodological benefits outweighed potential drawbacks.

VE 1 involved 18 teacher trainees, eight (seven female, one male) from a German university and ten (six female, four male) from a Polish university. All participants were enrolled in a Teaching English to Speakers of Other Languages (TESOL) masters training programme. In total 17 (94\%) participants completed the pre-test, and 15 (83\%) participants completed the post-test. In sum: the data set from this exchange provided a rich opportunity to explore students' learning and development using a mixed method approach and thus clear methodological benefits.

\subsection{VE 1}

This exchange took place over 13 weeks in the Winter term 2017/2018. Throughout the entire period, participants worked in intercultural teams. Weekly 1.5 hour meetings in the local classrooms were divided into: (1) 45 minutes in local teams for reflection on the exchange and the learning experience and (2) 45 minutes online in intercultural teams working on tasks. The participants used English as a lingua franca.

In their intercultural teams, participants worked on the design and peer evaluation of intercultural online-based tasks for their future English as a foreign language learners in primary and secondary schools, using a Moodle platform and its integrated tools, as well as social media such as WhatsApp. Following the experiential learning model, they experimented with various tools to get a feeling for their potential pedagogical use before engaging in collaborative task design in Phases 2 and 3.

During Phase 1, the 'getting-to-know each other' phase, participants posted short multimodal introductions on a Padlet ${ }^{8}$ wall so that all were gathered in a single virtual space to create a group

8. https://padlet.com/ 
feeling. Individual introductions were also posted in the respective Moodle group fora. In their intercultural teams, the trainees communicated synchronously via $\mathrm{Zoom}^{9}$, discovering its potential for immediate oral interaction and negotiation while deciding on a group name. For written communication, the participants used mainly Google Docs.

In Phase 2, the international teams evaluated an online task developed by student teachers in a previous VE. They discussed the use of technology and made suggestions as to how task design and technology application could be improved. These evaluations provided the backdrop for the teams' own task designs for technology-based intercultural learning, and aimed to foster their competence development in this respect. Next, the intercultural teams gave each other feedback on their tasks. Both the design and the peer feedback were then presented in the local classrooms, allowing for comprehensive reflection on the task design process and its outcomes.

This process was repeated in Phase 3: technology-based task design, peer feedback, local presentation, and reflection. However, this time, a more complex technology-based task sequence was designed and published on a website the participants created (using Weebly) to display their finished 'products'. Apart from Weebly, teams were asked to integrate at least three digital tools into their tasks.

\subsection{Procedure}

Figure 2 gives an overview of the data collection process. Each VE participant received a personalised email to complete the pre-test before getting access to the VE. Here is an example of one of the questions asked in the learner diary at pre-test stage:

"Can you give a concrete example (a lesson, a series of lessons, or even an entire class/ course) of how the use of technology has enhanced teaching or learning (a situation where you were either a learner or a teacher)? What was the topic and which tools and/or online environments were used?”

The questions were designed to broadly inform the areas addressed in the research sub-questions of the study - in our case digital-pedagogical competence development. At the end of the VE, each participant received a personalised email to complete the post-test.

9. https://zoom.us/ 


\section{Figure 2. EVALUATE data collection process}

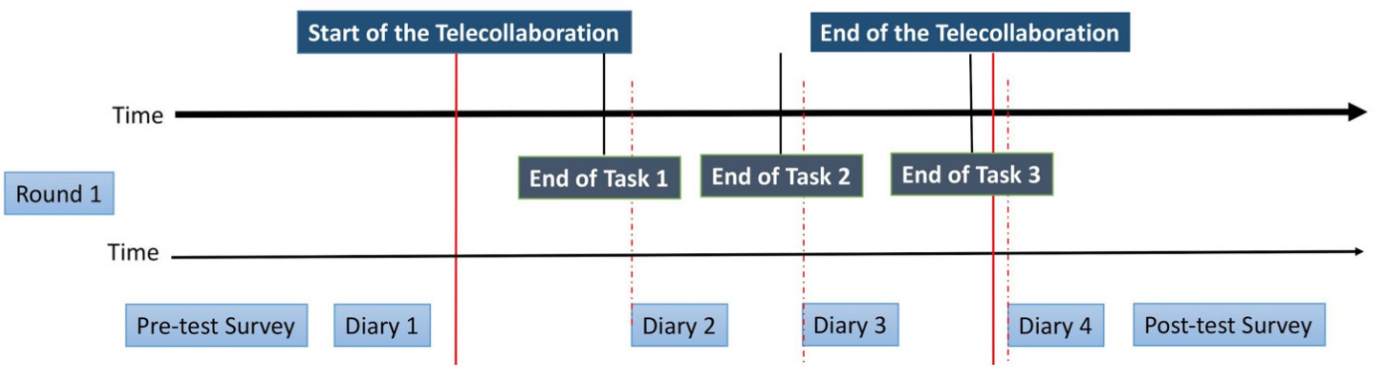

\subsection{Instruments used}

\subsubsection{Quantitative instruments}

As a proxy for growth in digital-pedagogical competencies, we used the TPACK instrument developed by Schmidt et al. (2009) in a pre-post manner. Koehler, Mishra, Akcaoglu, and Rosenberg (2013) confirmed that across several different TPACK survey instruments, researchers have found high levels of reliability which indicates that the items of the TPACK survey correctly focus on the individual factors comprising TPACK. In the current study, the 47 item questionnaire by Schmidt et al. (2009) was shortened to 17 items covering four out of the seven sub-constructs of the TPACK instrument: TK (seven items, $\alpha=.85$, "I can learn technology easily"); TCK (one item, "I can choose technologies that enhance the content for a lesson"); TPK (four items, $\alpha=.73$, "I can choose technologies that enhance the teaching approaches for a lesson"), and TPACK (five items, $\alpha=.81$, "I can select technologies to use in my classroom that enhance what I teach, how I teach, and what students learn”). Pre- and post-test Cronbach alpha values (testing the reliability of the scale in this study) were all above .7, indicating that the TPACK subscales used in this study were measured reliably. The list of items used in this study can be found in Appendix B. For a detailed description of the items, see The EVALUATE Group (2019).

\subsubsection{Qualitative instruments}

A substantial amount of qualitative data were collected from both the student teachers and the teacher trainers participating in the VEs. This allowed us to answer those questions which may not be addressed by a classic pre-test, post-test method. A mixed method approach is supported by 
Anderson (2008) who argued that "[o]ften a combination of qualitative and quantitative approaches is needed in cross-national research due to the highly diverse cultural contexts to be studied” (p. 91). Furthermore, in line with recommendations by Rienties et al. (2013a, 2013b), triangulating the quantitative with the qualitative data can explain divergent findings as regards the impact of the VEs on trainees' competence development.

The main qualitative data sources were as follows:

- pre- and post-exchange online or on-site interviews with focus groups from the participating classes and their teacher trainers;

- an online learner diary provided at key stages during the exchange with prompts focusing on the telecollaborative experience and its relationship to the development of digitalpedagogical competences and Intercultural Competence (IC);

- the online interactions and artefacts created by the students during the exchange; and

- the end of course reflection documents such as course portfolios or essays.

In VE 1, we also considered the transcripts of video-taped Face to Face (F2F) sessions (one camera per classroom capturing the instructor and students' discussions in the reflective phases, comprising approximately 40 hours of video material).

\subsection{Data analysis}

As recommended by Field (2013), we first analysed the quantitative data for missing values and tested the normality on the Dependent Variables (DV) using skewness and kurtosis measures, which indicated a normal distribution of all the DVs and its suitability for analysis using analysis of variance. Given that longitudinal data collection is sensitive to missing data (Torgerson \& Torgerson, 2008), we also tested whether there were any self-selection or non-response biases in the instruments but found no significant patterns in VE 1. Subsequently, we used ANOVA and simple effect analysis to test the impact of the training, using effect sizes to determine the impact of the respective tests.

Qualitative Content Analysis (QCA) was applied to the data (learner diaries). QCA is a well-established technique based on the interpretation of the content of text data, the identification of themes or patterns, and their systematic classification through codes (Zhang \& Wildemuth, 2009). For the qualitative data, two of the co-authors carried out an initial analysis of entries for Diary 1 and Diary 4 (see Figure 2) and allowed the categories and codes reflecting participants' digital-pedagogical learning experience emerge from this data. After considering inter-coder agreement, the codes were 
consolidated and the remainder of the diary entries as well as the additional qualitative data sources from VE 1 were coded accordingly. The following codes were used:

- technology used;

- challenges encountered when using technology for teaching;

- most important insights gained in terms of technology used;

- experienced benefit of technology use (self);

- projected benefit of technology use (students);

- methodological use of tools;

- technology chosen to enhance learning; and

- technology chosen to enhance teaching.

For representative examples of each code see The EVALUATE Group (2019) ${ }^{10}$.

\section{Results and discussion}

\subsection{Quantitative results}

Out of the 25 VEs in EVALUATE, VE 1 had a relatively low pre-TPACK score at the outset of the exchange: 3.41 out of 5 (see Figure 3). After 95 days, the TPACK scores of VE 1 participants substantially increased to 3.91, which amounts to a positive growth of $15 \%$. The results for the overall main effect of VE was significant $(F(1,13)=14.162, p<0.001, \mathrm{n} 2=.521)$ with large effect size. Most VEs had an average score of around 4.00 at the post-test. Thus it is safe to say that the majority of participants felt positive about the digital-pedagogical competencies they developed during the project.

Although this reflects a positive growth at VE level, not all participants benefited equally according to the quantitative measures of VE 1 (see Figure 4). Three trends can be identified:

First, Polish participants (purple) on average have higher pre-test scores, but the difference is not significant in comparison to German participants (blue) $(F(1,15)=.506, p>.05)$. However, the posttest scores showed that Polish participants on average scored significantly higher relative to the German participants $(F(1,13)=4.667, p<.05, \mathrm{n} 2=.265)$, showing a moderate effect size. In other words: the Polish participants had considerably higher (self-reported) digital competences at the end of VE 1 than the Germans.

10. https://www.evaluateproject.eu/evlt-data/uploads/2019/03/EVALUATE_EPE_2019.pdf; sections 4.5. 1 - 4.5.8 in particular 
Figure 3. Average growth in TPACK across 25 exchanges (pre-post-test)

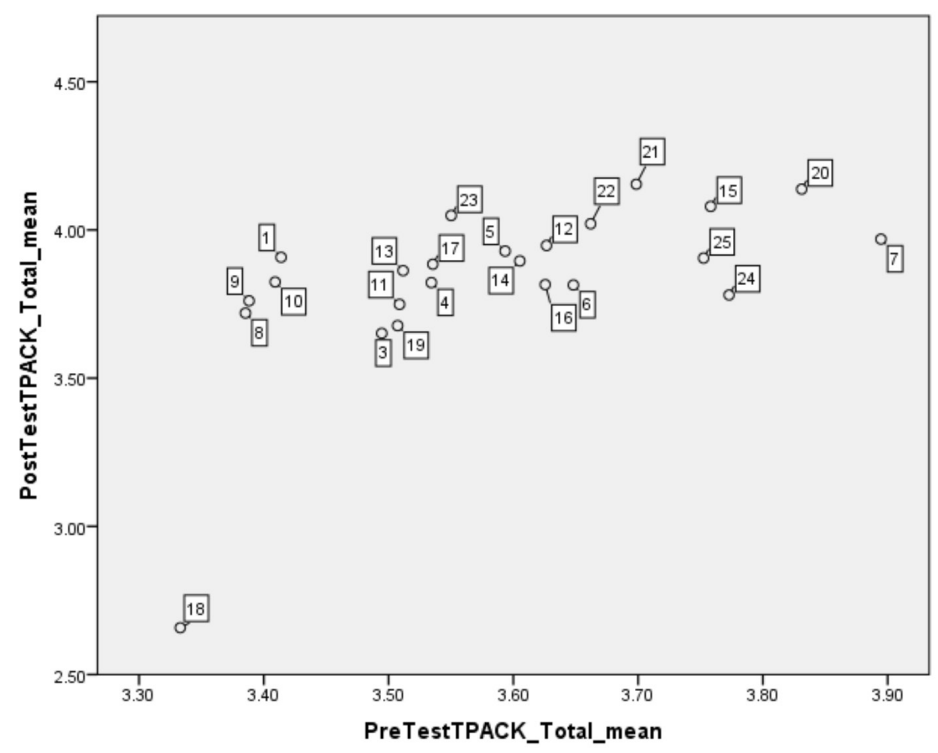

Figure 4. Growth in TPACK in VE 1 (pre-post-test)

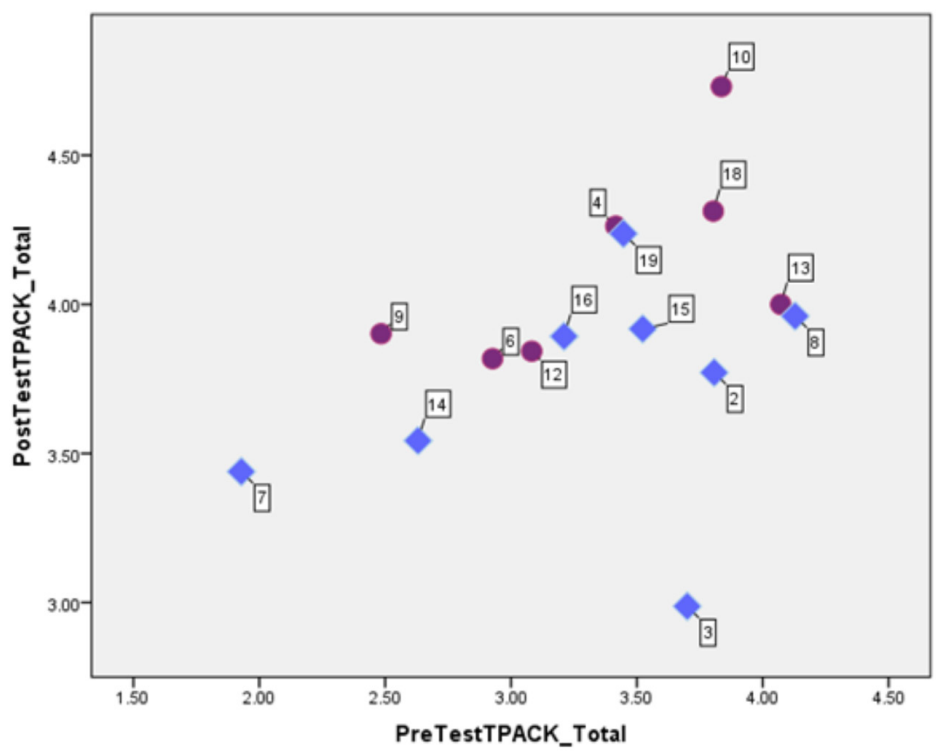


Second, even though Polish participants had a higher score, not every single participant increased their TPACK score over time. For example, although Participant 6 and Participant 9 made some gains, these were lower than those achieved by some of their peers (e.g. Participant 10, Participant 18).

Third, some of the German participants made a 'negative' gain over time, such as for example Participant 3, who started with 3.90 and ended with a below neutral TPACK score of 2.80. However, this does not necessarily imply that Participant 3 'unlearned' his/her digital competences. In line with the Dunning-Kruger effect (Dunning, 2011; Kruger \& Dunning, 1999), a reduction or limited change in students' self-assessment of this component may actually indicate greater awareness of the complexity of the process once they have experienced a VE.

Next, we will look at the lived experiences of some of the 18 participants to better understand why some achieved 'quantitative gains' in digital competences, while others did not.

\subsection{Qualitative results}

Before illustrating how the mixed methods design allowed for a more differentiated understanding of the quantitative data - by considering the learning process through the lens of the qualitative data - we share some general observations.

\subsubsection{General observations}

In general, the qualitative data analysis supports the quantitative findings as to student teachers' overall positive development of TPACK competencies. After Task 3 (see Figure 2), participants were asked the questions below.

- What have you learned so far about how technology influences your teaching approach? (D4Q1) 11

- Has this project affected in any way how you will use online tools and environments in your own teaching career in the future? (D4Q5)

- What is the most important thing you feel you have learned about how online tools and environments should be used for teaching? (D4Q6)

Here are a few representative diary entries from VE 1 participants which testify to their TPACK development. The targeted TPACK competences (see Section 2.2.1) are provided in brackets:

11. See Appendix A for an explanation of abbreviations. 
They report having learned about new tools and their pedagogical potential (TK/TPK):

"I have learned something about quite a few new online tools during this project, I especially liked Padlet. I think it is great for open discussions or the presentation of results" (Participant 8, female, German).

More specifically, they mention the pedagogical affordances of technology, allowing the transition from a more teacher- to a more learner-centred approach (TPK):

"I have learned that technology can open up a strict lesson plan, because there are so many options on how to incorporate it in class. If the teacher uses e.g. controlled platforms, the students can do research all by themselves, individual or in teams, in order to do a task. The teacher can focus on monitoring, but still needs to give good instructions beforehand" (Participant 14, female, German).

There is also evidence of subject specific TPK competence development, namely foreign language teaching:

"Yes, I learnt that the tools may be used in various aspects. One tool can be used for example for both grammar and reading or listening, etc.” (Participant 12, female, Polish).

"I would say that technology can support my teaching approach a lot since I put strong emphasis on communication. It offers the opportunity to stage real-life encounters inside the classroom where students are supposed to use the [foreign language] under real-life conditions in an authentic situation (when using Zoom, for example)" (Participant 7, male, German).

At the same time, they have become aware of challenges, taking a critical stance and highlighting the importance of pedagogically informed tool choices (TPK):

"They [the tools] should be connected with very clear instructions which deal with each exercise" (Participant 10, male, Polish).

"I learned that they [the tools] need to be chosen wisely, and that they should have a purpose. Sometimes they seem to be more interesting than traditional material, but they should improve the lesson and open it up. So they should be chosen after you set your lesson goal, and not chosen prior to this just to use an online tool” (Participant 8). 
The motivational aspect of online tools for their future learners is repeatedly described:

"I’ve learnt that using technology in classroom has a huge influence on learners' motivation and engagement” (Participant 12).

Finally, they also feel more confident about integrating technology into their future teaching practice:

"I was not too optimistic about using online tools in class (like Weebly, Zoom, learning apps...), because I didn’t quite know how to incorporate those kind of things in class. Now I am sure that I am going to use them in class” (Participant 14).

"Well, I am definitely going to deal with a couple of online tools and think about using them in my classroom for a communicative purpose” (Participant 7).

The next section takes account of the data context and highlights the benefits of a rich pool of qualitative data - forum posts, team negotiations in Google Docs, and reflections in the local classrooms - and the need for careful data triangulation when exploring the development of TPACKrelated competencies.

\subsubsection{Looking at two salient groups}

Considering the process of task negotiation and evaluation during the VE, a more comprehensive picture of TPACK development presents itself and provides a more nuanced and also different understanding from what the quantitative data show. In this process, the local F2F reflective phases of the blended learning format become especially important. To illustrate how the qualitative data sheds light on the quantitative findings, we focus on two transnational teams.

Team 1: Participant 7 (German) and Participants 1 and 10 (Polish)

The spotlight is on Participant 7 who shows rather low TPACK post-test results and on Participant 10 who shows good post-test results (see Figure 4).

Team 2: Participant 12 (Polish) and Participants 8 and 14 (German)

While Participants 8 and 12 have very good TPACK post-test results, Participant 14's results are rather poor. 
It is important to note that the differences in how the Master programmes are set up in Germany and Poland had a considerable impact on the intercultural interaction among the participants. The Polish students showed higher digital competence from the outset due to the fact that many had already taken a course on technology in foreign language education prior to the VE. In contrast, the German students showed a higher level of pedagogical competence in terms of the task design requirements in Phases 2 and 3 of the exchange. Many had already taken a class on Task-Based Language Learning (TBLL). These contextual 'advantages' and 'disadvantages' clearly impacted on all transnational teams.

\section{Team 1}

For Participant 7, who expected from the VE to "get familiar with modern communication technologies in the foreign language learning classroom" and to "gain some knowledge about the usage of such technologies from a teacher's perspective \& a student's perspective” (Forum 11/5/17), the tools used in the VE are new. When Participant 1 suggests Quizlet as a tool for one of the tasks, Participant 7 comments: "[I] dont know what Quizlet is” (GDC - IC task evaluation). Participants 1 and 10 on the other hand, make several suggestions to integrate tools into the tasks they negotiate. While Participant 1 proposes Quizlet, Participant 10 opts for PixaBay: "Pixabay may be helpful because learners can talk about their pictures” (GDC - Session 1 Weebly design). Participant 10, who is overall less active in the task design as such, eventually creates the Weebly site for the team to present the outcome of the last collaborative task in Phase 3.

While the distribution of digital competence in this team reflects quantitative post-test results, the distribution of pedagogical competence is a different matter.

Participant 10 approaches the use of technology from a skills-oriented angle, choosing a tool because it will facilitate a specific skill: "PixaBay may be helpful because learners can talk about their pictures which is speaking. We need reading, speaking, listening, vocabulary” (GDC - IC task evaluation). As the classes he took in the Polish Masters programme follow a skills-based approach to foreign language teaching, he does not have any concept of task-based learning, nor does he pursue an integrated skills approach to foreign language teaching. It is Participant 7 - enrolled in a Masters programme where TBLL concepts are extensively discussed - who looks at task design from a meaning-focused perspective, trying first to involve the learners with their ideas and building up a task sequence, before deciding which tools could be helpful to facilitate this approach. In his suggestions he often argues theory-based, explaining for example to his partners the function of a task's topic: "The topic of a task is very important, since it is meant to make the learners curious” (GDC - IC task evaluation). When designing the Weebly-based task sequence, Participants 1 and 10 quickly focus on tool choice 
whereas Participant 7 first tries to establish an understanding of the task: "Let's come up with some more questions [explains this in terms of the task] then we will think about the three online tools we would like to include and then we can narrow it down and create the task" (GDC - Session 2 Weebly design). Participant 7 also looks critically at tool suggestions to make sure that they are in line with a learner-centred task-based approach. When Participant 10 suggests: "So we can use video clip in the first activity just to encourage learners to talk" (GDC - Session 2 Weebly design), Participant 7 responds: "I would always be careful with pictures. Of course, they can be helpful, but especially in the introduction phase they can narrow down the ideas of the learners and at this point they are supposed to activate their pre-knowledge themselves” (GDC - Session 2 Weebly design).

Thus, Participant 7's low quantitative post-test score does not take into consideration the pedagogical expertise he brings to the task design process. Without his contributions, the team's task results would not have been as good in terms of the general characteristics of good tasks in TBLL, such as establishing a clear meaning focus, involving and with that motivating the learners by making them curious about the task content, and in choosing the right tool to facilitate learner-centredness, Participant 7 clearly developed in terms of TPACK, learning how to integrate tools into foreign language teaching as shown in the quotes above (Section 4.2.1). Participant 10 also learned from the exchange. With regard to what he learned about the use of online tools, he states "they should be connected with very clear instructions which deal with each exercise” (D4Q6). Apart from this reply though, there is very little in the qualitative data that shows that he developed in terms of a task-based approach to online tool integration. This was, however, one of the central methodological aims of the VE. One reason might be his lack of readiness for collaborative online work over an extended period of time as perceived by his partners. As a result, he is unable to benefit from his German partner's TBLL expertise. This was compounded by a lack of ability (or willingness) to engage in online communication, as the reflection after the teams' online interaction showed: "Exactly, he did it [designing the team's Weebly site], because he didn’t do anything at all before” (Participant 7 about Participant 10; Refl. 01/29/18).

Thus, the quantitative post-test results do not tell the whole story. The triangulation of the qualitative data offers deeper insights into the team's TPACK learning process. The relevance of the interpersonal dimension is also apparent in Team 2 where willingness to communicate and engage with partners leads to very positive results.

\section{Team 2}

At the outset, Participants 8 and 14 both express a need to develop their technical competence. While Participant 8 points out that she "already learned how to use Google Docs and the EVALUATE website“, she also says that she needs "to learn a lot more about technology in general, since they can 
improve your lessons a lot“ (Forum 10/29/17). Participant 14 would like to "get to know new online platforms to communicate with" and to "get more technical skills" (Forum 11/4/17). Both also profess a strong interest in how to integrate VE into their future classrooms.

"I hope that I will get a sense of how to integrate such a platform into my future classrooms" (Participant 8, Forum 10/29/17).

"Learn something about such a project and how it could be implemented in the classroom" (Participant 14, Forum 10/29/17).

Their Polish partner, Participant 12, supports these expectations:

"You're both right girls cause in order to be a teacher in the future we cannot teach only by methods that were used for ages. I know that those old methods work but we cannot stop by that. We have to learn and develop our technological knowledge” (Forum 10/29/17).

While Participant 12 - similar to the Polish partners in Team 1 - brings more technical competence to the exchange, the German students are - again - more knowledgeable in task-based design. In one of the reflections, Participant 12 talks about role distribution in her team:

Participant 12: "Yeah, and I was the person who was trying to do something more technological."

Teacher: "Are you comfortable with that?"

Participant 12: "Yeah - because the girls have many ideas and I try to make them more... technical?”

Teacher: “Technology friendly?”

Participant 12: "Yeah.”

Teacher: "So you have the technology expertise in your groups, right?"

Participant 12: "Yeah - because they didn’t have such classes as we did last year.”

(Refl. 11/12/2017). 
The tasks Team 2 had to evaluate and design in the last two phases of the VE are better developed since the three students collaborate more closely. They relate better to each other than the students in Team 1 where Participant 10 for a long time is afraid of really engaging in synchronous communication:

Teacher: "He had problems with interacting online, right?”

Participant 7: “Yes.”

(Refl. 01/29/18)

Participant 12 also has some experience of using technology in the foreign language classroom which probably helped her to better understand her German partners' task suggestions and thus to make the link between theory and classroom practice. Two critical incidents show this.

Participant 8 (high post-test TPACK score) negotiated the intercultural task evaluation of another team, who called themselves the Music Junkies, alone with Participant 12 since Participant 14 was sick. While Participant 8 looked at online task design from the Task-Based Language Teaching (TBLT) perspective, Participant 12 focused on technology. In the following exchange, they discuss the warmup phase of the Music Junkies' intercultural task on New Year's Eve traditions.

In the warm-up phase, the teacher, after having presented "flashcard/PowerPoint presentation with pictures connected with New Year's Eve” to have the learners guess the topic of the lesson, s/he has the learners work in pairs in the next step: "Learners think about their personal traditions and habits connected with New Year's Eve, work in pairs and write down some of their traditions, then they share their traditions with their classmates” (intercultural task Music Junkies).

Participant 8: "I think it is okay to activate their pre knowledge and give them opportunity to talk which is always good and it is personal and meaningful to them.”

\section{(...)}

Participant 12: "I think also that it is good for the learners not to use the technologies all the time so brainstorming and discussion is a great option”

(GDC - IC task evaluation). 
While Participant 8 analyses the task positively from a TBLL perspective (activating learners' preknowledge, involving learners, providing a topic for meaningful communication), Participant 12 looks critically at technology use and supports Participant 8 in her analysis. When looking at technology use in their partner team's task, it is Participant 8 who follows Participant 12's lead. In Step 4 of the task sequence they design, the Music Junkies suggest: “On the basis of what they've found out, the learners prepare a story about their partner's New Year's Eve tradition with the use of Storybird" (IC task Music Junkies). Participant 12 is not convinced by Storybird and they discuss different technical alternatives. Participant 8 suggests well-known tools such as PowerPoint:

Participant 12: "We can offer some other platform instead of Storybird. Do you know any that will be more appropriate?"

Participant 8: "[I] think PowerPoint or [Prezi] is sufficient easier but maybe it is good to introduce them to new platforms to so i think it depends if they know that already *too (...).”

Participant 12: “Isn’t a [Piktochart] the same?”

Participant 8: "I am not familiar with [Piktochart].”

(GDC - IC task evaluation)

While Participant 12's technological knowledge allows her to suggest a new tool, Participant 8 can only think of traditional presentation tools, but seems open to using a different tool. In the end they reach a compromise underpinned by an argument why Storybird might not be the best choice. Here, Participant 12(P) clearly shows her TPK since she considers tool choice from the learners' perspective, making the case for a student-oriented and with that a task-based approach offering learners more choice. Their comment on the Music Junkies’ intercultural task reads as follows:

"Storybird is a cool method, but you can’t include your 'own' pictures, just the ones that are provided on Storybird and it takes a while to understand the platform”.

"Good to introduce them to new options like Storybird, just takes time to create one. Maybe PowerPoint or [Piktochart] would be easier and they could add photos” (IC Task evaluation).

When the team works on their second technology-based task, the Weebly-based intercultural task, Participant 8 is sick, and Participant 12 works with Participant 14 (low post-test TPACK score). Again, the two students pool their different competencies to create a meaningful task. While Participant 
14 explains aspects of TBLT to Participant 12, and how to integrate intercultural communicative competence into the task design, Participant 12 thinks about how to match the pedagogical approach with the right tool choice.

Participant 12: "I'm not sure if I understand this sentence: 'What is the target task you tell your students about' properly.”

Participant 14: "Well there is always a huge task where everything else is built up on... like a presentation or something where others can see the outcome.”

Participant 12: “The main task that will be preceded by a few smaller tasks?”

Participant 14: "Should always be the most meaningful task almost... the very last task as a result.”

Participant 12: "So instead just a simple PowerPoint presentation we can use http://prezi. com/learn/.”

Participant 14: "Prezi sounds fun, I just read through the tools... have you ever used it before?”

Participant 12: "A few of them during my IT classes two years ago"

(GDC - Weebly design).

Finally, Participant 12 suggests a design integrating the necessary tools:

"Maybe choosing a famous person from your country, make a Prezi about him/her put it on the Padlet where your abroad partners can read it and then interviewing each other via Zoom us to check their knowledge about the famous person you have chosen for them" (GDC - Weebly design).

Hence, Participant 12 learns about TBLL and Participant 14 finds out about technology use. While Participant 14's post-test TPACK results are not good, she - like Participant 7 in Team 1 - shows a very good grasp of the pedagogical dimensions of task design. Thanks to her tech-proficient partner, she also begins to develop TK as reflected in her post-exchange comments (see Section 4.2.1). Again qualitative data triangulation allows for a better understanding of TPACK development. The 
different set-up of their Masters programmes had students focus on different competences in foreign language teaching, but by collaborating, they pooled their expertise in technology-based task design, developing their digital PCK together.

What conclusions can be drawn from these observations?

\section{Concluding remarks}

There are obviously limitations in our study. First of all, we focused only on one VE with 18 participants, which restricts the transferability of our findings to other contexts. Next, we specifically sampled a VE with a low TPACK score at the outset and went on to unpack how the German and Polish teacher trainees' skills and competences improved. However, it is important to test whether the same pattern of improvement is present in other exchanges.

All quantitative data collected was self-report data with obvious and known biases. However, given the high response rates throughout the various measurements, the high reliability of the used scales in this study, and the normal distribution of the data, the results of the quantitative study can be considered robust. Furthermore, with the triangulation of the various qualitative data sources, a relatively complex narrative emerged.

Through our research, we sought to shed light on the impact of VE on student teachers' digitalpedagogical competence development. Our data analyses testify to the participants' development of TPACK competences during their exchanges and we can therefore claim with some confidence that the chosen methodology has provided the evidence required by education decision makers for the integration of VE into (languages) teacher education programmes. Thus the EVALUATE EPE confirms Chai et al.'s (2013) conclusion that survey studies exploring student perceptions and experiences with learning with technology and including student teachers provide important information to help ministry and schools in planning education programmes.

Yet, the quantitative analysis of the German-Polish EVALUATE VE also showed that competence development was distributed quite unevenly among participants, with Polish participants generally displaying higher post-test results than their German counterparts. The qualitative data analysis then, presented a more differentiated picture, particularly with regard to digital pedagogical-competence. This is also in line with Chai et al. (2013) who have pointed to the strong interdependence between teachers' beliefs, competencies, and context, and have argued that "enhancing teachers' TPACK is a necessary but insufficient condition for widespread pedagogical use of ICT” (p. 39). 
Furthermore, our insights corroborate Rosenberg and Koehler's (2015) observations about the relevance of educational contexts and their impact on student teachers' digital-pedagogical competence development - in our case reflected in the participants' ability to design technologybased tasks informed by TBLL parameters. Both teams in VE 1 brought important competencies to the task design negotiations. Yet - as pointed out by Chai et al. (2010) - the competence of pedagogically informed tool choice and integration proved to be crucial - an aspect which would not have come to the fore, had we only considered the quantitative post-test results. This highlights the limitations of self-report data such as the survey results from the EVALUATE TPACK study, when trying to understand the development of competence clusters (e.g. TPACK).

Since in VE-based ITE interaction and collaboration are the preconditions for 'designerly thinking' in terms of task creation for learning with technology, the group processes underpinning the competence development among trainee teachers also need to be considered. The evolving dynamics in the two teams examined here speak to Chai et al.'s (2013) assertion: while "teachers have to assume the epistemic agency and appropriate 'design literacy' which is characterized by flexibility and creativity (Kereluik et al., 2011), [...] design work is best carried out in groups” (p.46).

Apart from these interpersonal factors, intrapersonal factors such as willingness to communicate are a basic requirement for engaging with the partner(s) and being able to benefit from the exchange, as a number of studies have shown (Cao \& Philp, 2006; Reinders \& Wattana, 2014). Another important impact factor on competence development is the teaching experience student teachers bring to these exchanges. If they already have a grasp of the classroom situation when working with technology because they have done a teaching practice or teach already, they also seem to be in a better position to negotiate new teaching methodologies. This was clearly the case for Participant 12 who profited from her partners' input when designing TBLL informed online tasks. Qualitative data analysis thus allowed to understand the competence she brought to the exchange and the development she underwent while closely collaborating with her peers which, in turn, showed her rather unexceptionable TPACK score in a very different light.

The mixed methods approach applied in this study - including the triangulation of quantitative and qualitative data sources - has demonstrated that different data sets are required to fully comprehend the processes involved in the development of TPACK through VE. As pointed out by Rienties et al. (2013a, 2013b), the mixed methods approach allowed us to put high and low quantitative scores of participants into perspective. By choosing a more robust research approach (Lawless \& Pellegrino, 2007; Stes et al., 2010) we could illustrate that being engaged in VE afforded the teachers of tomorrow to acquire competencies required for the classrooms of tomorrow. 


\section{References}

Anderson, R. (2008). Large-scale quantitative research on new technology in teaching and learning. In J. Coiro, M. Knobel \& C. Lankshear (Eds), Handbook of research on new literacies (pp. 67-102). Lawrence Earlbaum Associates. Arnold, N., \& Ducate, L. (2006). Future foreign language teachers' social and cognitive collaboration in an online environment. Language Learning \& Technology, 10(1), 42-66.

Belz, J. A. (2003). From the special issue editor. Language Learning \& Technology, 7(2), 2-5. http://lit.msu.edu/vol7num2/ speced.html

Belz, J. A., \& Thorne, S. L. (Eds). (2006). Internet-mediated intercultural foreign language education. Annual Volume of the American Association of University Supervisors and Coordinators. Heinle \& Heinle.

Cao, Y., \& Philp, J. (2006). Interactional context and willingness to communicate: a comparison of behavior in whole class, group and dyadic interaction. System, 34(4), 480-493.

Chai, C. S., Koh, J. H. L., \& Tsai, C.-C. (2010). Facilitating preservice teachers’ development of technological, pedagogical, and content knowledge (TPACK). Educational Technology \& Society, 13(4), 63-73.

Chai, C. S., Koh, J. H. L., \& Tsai, C.-C. (2013). A review of technological pedagogical content knowledge. Educational Technology \& Society, 16(2), 31-51.

Desjardins, F., \& Peters, M. (2007). Single-course approach versus a program approach to develop technological competencies in preservice language teachers. In M. A. Kassen, R. Z. Lavine, K. Murphy-Judy \& M. Peters (Eds), Preparing and developing technology-proficient L2 teachers (pp. 3-21). CALICO Publications.

Dooly, M. (2008). Understanding the many steps for effective collaborative language learning. Language Learning Journal, 36(1), 95-78.

Dunning, D. (2011). The Dunning-Kruger effect: on being ignorant of one’s own ignorance. In J. M. Olson \& M. P. Zanna (Eds), Advances in experimental social psychology (Vol. 44, pp. 247-296). Academic Press.

ET2020. (2015). Shaping career-long perspectives on teaching. A guide on policies to improve initial teacher education. The education and training 2020 working group on schools policy. https://www.noexperiencenecessarybook.com/ a21EQ/a-guide-on-policies-to-improve-initial-teacher-education.html

European Commission. (2015a). Erasmus - facts, figures \& trends. The European Union support for student and staff exchanges and university cooperation in 2013-14. Publications Office of the European Union. https://ec.europa.eu/ assets/eac/education/library/statistics/erasmus-plus-facts-figures_en.pdf

European Commission. (2015b). European education and training monitor. Online report. http://ec.europa.eu/dgs/ education_culture/repository/education/library/publications/monitor15_en.pdf

Field, A. (2013). Discovering statistics using IBM SPSS statistics (4th ed.). SAGE.

Fuchs, C. (2006). Computer-mediated negotiation across borders: German-American collaboration in language teacher education. Peter Lang.

Fuchs, C., Hauck, M., \& Müller-Hartmann, A. (2012). Promoting learner autonomy through multiliteracy skills development in cross-institutional exchanges. Language Learning \& Technology, 16(3), 82-102. 
Groth, R., Spickler, D., Bergner, J., \& Bardzell, M. (2009). A qualitative approach to assessing technological pedagogical content knowledge. Contemporary Issues in Technology and Teacher Education, 9(4), 392-411.

Guikema, J. P., \& Menke, M. R. (2014). Preparing future foreign language teachers: the role of digital literacies. In J. P. Guikema \& L. Williams (Eds), Digital literacies in foreign and second language education (Vol. 12, pp. 265-287). CALICO Publications.

Guth, S., \& Helm, F. (2010). Introduction. In S. Guth \& F. Helm (Eds), Telecollaboration 2.0: language, literacy and intercultural learning in the 21st century (pp. 13-38). Peter Lang.

Hauck, M. (2007). Critical success factors in a TRIDEM exchange. ReCALL, 19(2), 202-223.

Hauck, M., \& Kurek, M. (2017). Digital literacies in teacher preparation. In S. L. Thorne \& S. May (Eds), Language, education and technology, Encyclopedia of language and education (3rd ed., pp. 275-287). Springer International Publisher.

Helm, F. (2014). Developing digital literacies through virtual exchange. Elearning Papers, 38, 1-10.

Jonassen, D. H., Peck, K. L., \& Wilson, B. G. (1999). Learning with technology: a constructivist perspective. Prentice Hall.

Kereluik K., Mishra P, \& Koehler, M. J. (2011). On learning to subvert signs: literacy, technology and the TPACK framework. California Reader, 44(2),12-18.

Kern, R., \& Warschauer, M. (2000). Network-based language teaching: concepts and practice. Cambridge University Press. Kimmons, R. (2015). Examining TPACK's theoretical future. Journal of Technology and Teacher Education, 23(1), 53-77.

Kinginger, C., \& Belz, J. A. (2005). Sociocultural perspectives on pragmatic development in foreign language learning: case studies from telecollaboration and study abroad. Intercultural Pragmatics, 2, 369-421.

Koehler, M. J., \& Mishra, P. (2005). Teachers learning technology by design. Journal of Computing in Teacher Education, 21(3), 94-102.

Koehler, M. J., Mishra, P., Akcaoglu, M., \& Rosenberg, J. M. (2013). The technological pedagogical content knowledge framework. In J. M. Spector, M. D. Merrill, J. Elen \& M. J. Bishop (Eds), Handbook of research on educational communications and technology (pp. 101-111). Springer.

Kramarski, B., \& Michalsky, T. (2009). Three metacognitive approaches to training pre-service teachers in different learning phases of technological pedagogical content knowledge. Educational Research and Evaluation, 15(5), 465-485.

Kramarski, B., \& Michalsky, T. (2010). Preparing preservice teachers for self-regulated learning in the context of technological pedagogical content knowledge. Learning and Instruction, 20(5), 434-447.

Kruger, J., \& Dunning, D. (1999). Unskilled and unaware of it: how difficulties in recognizing one's own incompetence lead to inflated self-assessments. Journal of Personality and Social Psychology, 77(6), 1121-1134.

Kurek, M., \& Hauck, M. (2014). Closing the "digital divide" - a framework for multiliteracy training. In G. Pettes Guikema \& L. Williams (Eds), Digital literacies in foreign and second language education: research, perspectives, and best practice (pp. 119-140). CALICO Publications.

Kurek, M., \& Turula, A. (2014). Digital autonomy-wishful thinking or reality? On teacher attitudes to Web 2.0 tools. In M. Dedigovic (Ed.), Attitudes to technology in ESL/EFL pedagogy (pp. 112-128). TESOL Arabia Publications.

Lawless, K. A., \& Pellegrino, J. W. (2007). Professional development in integrating technology into teaching and learning: knowns, unknowns, and ways to pursue better questions and answers. Review of Educational Research, 77(4), 575-614. 
Lewis, T., Chanier, T., \& Youngs, B. (2011). Multilateral online exchanges for language and culture learning. LLT, 15(1), 3-9. Mishra, P., \& Koehler, M. J. (2006). Technological pedagogical content knowledge: a framework for teacher knowledge. Teachers College Record, 108(6), 1017-1054.

Müller-Hartmann, A. (2006). Learning how to teach intercultural communicative competence via telecollaboration: a model for language teacher education. In J. A. Belz \& S. L. Thorne (Eds), Internet-mediated intercultural foreign language education (pp. 63-84). Thomson Heinle.

Nicholas, H., \& Ng, W. (2012). Factors influencing the uptake of a mechatronics curriculum initiative in five Australian secondary schools. International Journal of Technology and Design Education, 22(1), 65-90.

Niess, M. L. (2005). Preparing teachers to teach science and mathematics with technology: developing a technology pedagogical content knowledge. Teaching and Teacher Education, 21(5), 509-523.

O’Dowd, R. (Ed.). (2006). Online intercultural exchange. An introduction for foreign language teachers. Multilingual Matters.

O’Dowd, R. (2007). Online intercultural exchange. An introduction for foreign language teachers. Multilingual Matters.

O’Dowd, R. (2018). From telecollaboration to virtual exchanges: state-of-the-art and the role of UNICollaboration in moving forward. Journal of Virtual Exchange, 1, 1-23. https://doi.org/10.14705/rpnet.2018.jve.1

O’Dowd, R., \& Lewis, T. (Eds). (2016). Online intercultural exchange: policy, pedagogy, practice. Routledge studies in language and intercultural communication. Routledge. https://doi.org/10.4324/9781315678931

O’Dowd, R., \& Ritter, M. (2006). Understanding and working with "failed communication" in telecollaborative exchanges. CALICO Journal, 23(3), 623-642.

O’Dowd, R., \& Ware, P. (2009). Critical issues in telecollaborative task design. Computer Assisted Language Learning, 22(2), 173-188.

O’Rourke, B. (2006). The problem of data in L2 computer-mediated communication research. In M. Koetter, O. Traxel \& S. Gabel (Eds), Investigating and facilitating language learning (pp. 131-144). Wissenschaftlicher Verlag.

Reinders, H., \& Wattana, S. (2014). Can I say something? The effects of digital game play on willingness to communicate. Language Learning \& Technology, 18(2), 101-123.

Rienties, B., Brouwer, N., Bohle Carbonell, K., Townsend, D., Rozendal, A. P., Van der Loo, J., \& Dekker, P. (2013a). Online training of TPACK skills of higher education scholars: a cross-institutional impact study. European Journal of Teacher Education, 36(4), 480-495. https://doi.org/10.1080/02619768.2013.801073

Rienties, B., Brouwer, N., \& Lygo-Baker, S. (2013b). The effects of online professional development on higher education teachers' beliefs and intentions towards learning facilitation and technology. Teaching and Teacher Education, 29, 122-131. https://doi.org/10.1016/j.tate.2012.09.002

Rogaten, J., Rienties, B., Sharpe, R., Cross, S., Whitelock, D., Lygo-Baker, S., \& Littlejohn, A. (2019). Reviewing affective, behavioural, and cognitive learning gains in higher education. Assessment \& Evaluation in Higher Education, 44(3), 321-337. https://doi.org/10.1080/02602938.2018.1504277

Rosenberg, J. M., \& Koehler, M.J. (2015). Context and technological pedagogical content knowledge (TPACK): a systematic review. Journal of Research on Technology in Education 47(3),186-210. https://doi.org/10.1080/15391 523.2015 .1052663 
Schmidt, D. A., Baran, E., Thompson, A. D., Koehler, M. J., \& Mishra, P. (2009). Technological pedagogical content knowledge (TPACK): the development and validation of an assessment instrument for preservice teachers. Journal of Research on Technology in Education, 42(2), 123-149. https://doi.org/10.1080/15391523.2009.10782544

So, H., \& Kim, B. (2009). Learning about problem based learning: student teachers integrating technology, pedagogy and content knowledge. Australasian Journal of Educational Technology, 25(1), 101-116.

Stes, A., Min-Leliveld, M., Gijbels, D., \& Van Petegem, P. (2010). The impact of instructional development in higher education: the state-of-the-art of the research. Educational Research Review, 5(1), 25-49.

The EVALUATE Group. (2019). Evaluating the impact of virtual exchange on initial teacher education: a European policy experiment. Research-publishing.net. https://doi.org/10.14705/rpnet.2019.29.9782490057337

Torgerson, D. J., \& Torgerson, C. (2008). Designing randomised trials in health, education and the social sciences: an introduction. Palgrave Macmillan.

Ware, P., \& O’Dowd, R. (2008). Peer feedback on language form in telecollaboration. Language Learning \& Technology, 12(1), 43-63.

Zhang, Y., \& Wildemuth, B. M. (2009). Qualitative analysis of content. In B. M. Wildemuth (Ed.), Applications of social research methods to questions in information and library science (pp.1-12). Libraries Unlimited.

\section{Appendices}

\section{Appendix A}

\begin{tabular}{|l|l|}
\hline Abbreviation & Explanation \\
\hline D4Q1 & Learner Diary entry 4 Question 1 \\
\hline Forum 14/11/17 & Post in a Moodle group forum \\
\hline GDC & Google Doc Chat on a specific task \\
\hline Refl. $01 / 29 / 18$ & F2F reflection in a local classroom \\
\hline
\end{tabular}

\section{Appendix B}

TPACK survey adopted from Schmidt et al (2009) containing items relating to technology use in learning.

\begin{tabular}{|c|c|c|c|c|c|}
\hline & SD & D & $\mathrm{N}$ & A & SA \\
\hline 1. I know how to solve my own technical problem & & & & & \\
\hline 2. I can learn technology easily. & & & & & \\
\hline 3. I keep up with important new technologies. & & & & & \\
\hline 4. I frequently play around with the technology. & & & & & \\
\hline 5. I know about a lot of different technologies. & & & & & \\
\hline
\end{tabular}




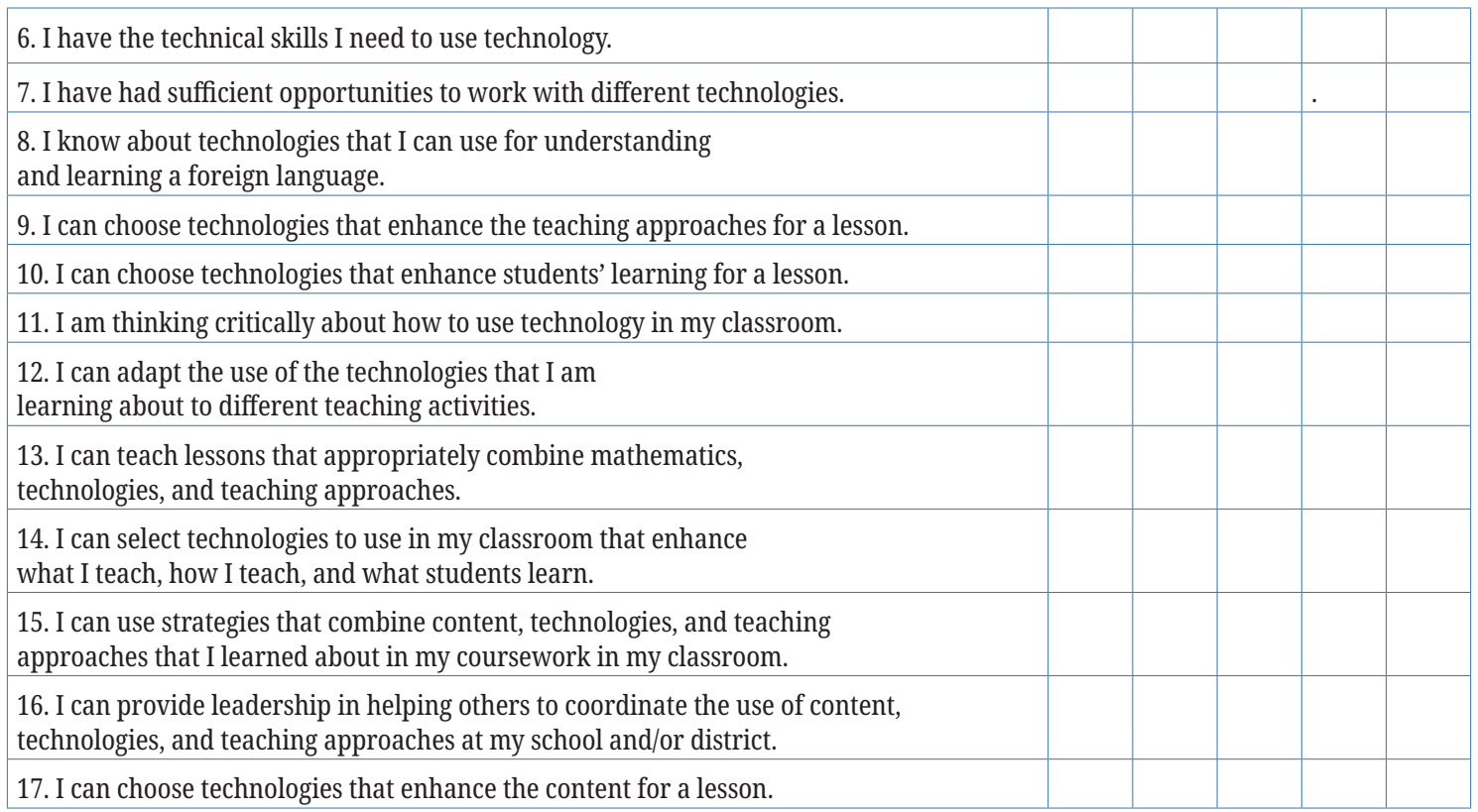




\section{Virtual Exchange?}

Published by University of Groningen Press | UGP, a not-for-profit press

Groningen, The Netherlands | UGP@rug.nl

(C) 2020 UNICollaboration (collective work)

(C) 2020 by Authors (individual work)

Journal of Virtual Exchange 2020

Edited by Carolin Fuchs, Cecilia Kennedy, and Müge Satar

Special issue edited by Marco Cappelini, Müge Satar, and Christelle Combe

Publication date: 2020/04/16

Journal of Virtual Exchange (JVE) is an online, open-access, peer-reviewed journal aimed at practitioners and researchers in the field known variously as virtual exchange, telecollaboration, or online intercultural exchange. It is the official journal of UNICollaboration (https://www.UNICollaboration.org/), the international academic organisation dedicated to supporting and promoting telecollaboration and virtual exchange in higher-level education.

Rights. The whole volume is published under the Attribution-NonCommercial-NoDerivatives 4.0 International licence (CC BY-NCND 4.0); individual articles may have a different licence. Under the CC BY-NC-ND licence, the volume is freely available online for anybody to read, download, copy, and redistribute provided that the author(s), editorial team, and publisher are properly cited. Commercial use and derivative works are, however, not permitted.

Disclaimer. University of Groningen Press does not take any responsibility for the content of the pages written by the authors of this article. The authors have recognised that the work described was not published before, or that it was not under consideration for publication elsewhere. While the information in this article is believed to be true and accurate on the date of its going to press, neither UniCollaboration nor University of Groningen Press can accept any legal responsibility for any errors or omissions. Additionally, the publisher makes no warranty, expressed or implied, with respect to the material contained herein. While University of Groningen Press is committed to publishing works of integrity, the words are the authors' alone.

Trademark notice. Product or corporate names may be trademarks or registered trademarks, and are used only for identification and explanation without intent to infringe.

Copyrighted material. Every effort has been made by the editorial team to trace copyright holders and to obtain their permission for the use of copyrighted material in this article. In the event of errors or omissions, please notify the publisher of any corrections that will need to by incorporated in future editions of this article.

Typeset by Research-publishing.net (https://research-publishing.net)

Noto fonts are open source. All Noto fonts are published under the SIL Open Font License, Version 1.1. Noto is a trademark of Google Inc. (https://www.google.com/get/noto/).

ISSN: 2647-4832 (online only)

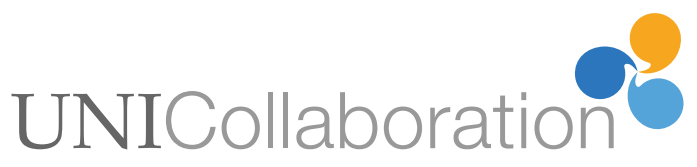

